\title{
Efficacy of side-to-end anastomosis to prevent anastomotic leakage after anterior resection for rectal cancer
}

\author{
HIROCHIKA KATO $^{1}$, TAKASHI ISHIDA ${ }^{1,2}$, NOBUHIRO NITORI ${ }^{1}$, AYU KATO ${ }^{1}$, TAKUYA TAMURA ${ }^{1}$, \\ SHUNICHI IMAI $^{1}$, TAKASHI OYAMA ${ }^{1,2}$, ATSUSHI KATO ${ }^{1}$, TAKASHI HATORI ${ }^{1}$, JUMPEI NAKADAI ${ }^{3}$, \\ SHIMPEI MATSUI ${ }^{4}$, MASASHI TSURUTA $^{2}$, MASARU MIYAZAKI $^{1,2}$ and OSAMU ITANO ${ }^{1,2}$ \\ ${ }^{1}$ Department of Digestive Disease Center, International University of Health and Welfare Mita Hospital, \\ Minato-ku, Tokyo 108-8329; ${ }^{2}$ Department of Hepato-Biliary-Pancreatic and Gastrointestinal Surgery, \\ School of Medicine, International University of Health and Welfare, Narita, Chiba 286-8520; \\ ${ }^{3}$ Department of Surgery, Saitama City Hospital, Midori-ku, Saitama, Saitama 336-8522; \\ ${ }^{4}$ Department of Surgery, Keio University, School of Medicine, Shinjuku-ku, Tokyo 160-8582, Japan
}

Received March 31, 2021; Accepted August 4, 2021

DOI: $10.3892 / \operatorname{mco} .2021 .2477$

\begin{abstract}
The present study aimed to investigate whether side-to-end anastomosis could provide an improved surgical outcome, such as lower anastomotic leakage rate, compared with end-to-end anastomosis, following anterior resection for rectal and rectosigmoid cancer. This retrospective study included 162 patients with rectal cancer who underwent elective anterior resection between January 2012 and October 2019 at a single institution. Patients with double cancers or colonic J-pouch were excluded. Anastomotic leakage was defined clinically and radiologically. Side-to-end anastomosis was introduced in the International University of Health and Welfare Mita Hospital in January 2017. Side-to-end anastomosis was performed in 63 patients, while end-to-end anastomosis was performed in 99 patients. Tumors tended to be located lower in the rectum in the side-to-end anastomosis group than in the end-to-end anastomosis group. No significant differences were observed in other patient characteristics. The incidence of anastomotic leakage was significantly lower in the side-to-end anastomosis group than in the end-to-end anastomosis group $(3 / 63,4.8 \%$ vs. $18 / 99,18.2 \%$, respectively, $\mathrm{P}=0.02)$. No significant differences were observed in the incidence rates of other complications. Univariate and multivariate analyses revealed that a smoking habit $(\mathrm{P}=0.04)$ and side-to-end anastomosis $(\mathrm{P}=0.02)$ were significantly associated with anastomotic leakage. In conclusion, side-to-end anastomosis using a
\end{abstract}

Correspondence to: Dr Takashi Ishida, Department of Hepato-Biliary-Pancreatic and Gastrointestinal Surgery, School of Medicine, International University of Health and Welfare, 852 Hatakeda, Narita, Chiba 286-8520, Japan

E-mail: t.ishida-3@iuhw.ac.jp

Key words: side-to-end anastomosis, anastomotic leakage, anterior resection double-stapling technique following anterior resection for rectal cancer may prevent anastomotic leakage.

\section{Introduction}

Anterior resection (AR) for rectal and rectosigmoid (RS) cancer has become a standard procedure, thus improving oncological and surgical outcomes because of advances in surgical strategy and perioperative management. Despite these advances, anastomotic leakage (AL) is an important complication that occurs during the acute phase after AR; the anastomotic leakage rate, regardless of temporary stoma use, varies from $2 \%$ to $15 \%$ among reports (1-3).

$\mathrm{AL}$ is associated with poor functional outcome, reduced quality of life, and prolonged hospital stay, as well as with poor oncological outcomes (e.g., morbidity, mortality, and recurrence rate) (4-7). Patient-related and operative factors have been reported in many studies as risk factors for the development of AL (8). For example, male sex, body mass index (BMI), level of anastomosis, absence of a diverting stoma, use of neoadjuvant therapy, and absence of a trans-anal tube have been reported as risk factors (8-13). Many of these factors remain controversial; however, surgical techniques related to blood flow, pressure, and tension at the anastomosis site play important roles in prevention of AL (14-18).

Blood flow is reportedly better at the antimesenteric border than at the end of the colon (14); moreover, blood flow at the anastomotic site is associated with AL (14-18). Therefore, blood flow at the side-to-end anastomotic site can be better than that at the end-to-end anastomotic site, and a side-to-end anastomosis can reduce the rate of AL after AR. The principle of a side anastomosis in gastrointestinal surgery is well recognized; it is considered a standard technique for esophagojejunal anastomosis. However, this approach is much less frequently used in colorectal surgery; few studies have directly compared side-to-end anastomosis and end-to-end anastomosis (19-21).

In our hospital, side-to-end anastomosis with a trans-anal double-stapling technique has been performed since 
January 2017 as the preferred procedure to prevent AL, along with a trans-anal tube and intraoperative indocyanine green fluorescence angiography (ICG-FA). The purpose of this study was to investigate whether side-to-end anastomosis could provide better surgical outcomes, compared to end-to-end anastomosis, following AR for rectal and RS cancer. In addition, this study identified factors associated with AL using univariate and multivariate analyses.

\section{Materials and methods}

Patients. This single-center retrospective observational clinical trial at International University of Health and Welfare Mita Hospital enrolled 178 patients with rectal and RS cancer who had undergone elective AR from January 2012 to October 2019. To examine the association between anastomosis type and surgical outcome, three patients with double cancers, eight patients with a colonic J-pouch, and five patients with trans-anal hand-sewn anastomoses were excluded. Therefore, 162 patients were included in this study; all underwent anastomosis with the application of a trans-anal double-stapling technique. Of the 162 patients, 63 underwent side-to-end anastomosis following AR. The flow chart of patient inclusion criteria is shown in Fig. 1. Patient characteristics and surgical outcomes were recorded. The descriptions and diagnoses of the cancers were performed in accordance with the Japanese classification of colorectal cancer. The treatment policy was decided in accordance with the Japanese Society for Cancer of the Colon and Rectum 2019 guidelines for the treatment of colorectal cancer. This study was approved by the institutional review board of the International University of Health and Welfare Mita Hospital (approval no. 5-19-41).

Surgical procedure. Anterior resections were performed by a laparoscopic or open approach. Blood vessels were ligated, lymph nodes were dissected, and the colon and rectum were mobilized; the rectum was then resected with a linear stapler at the anal side of the resection range. In the laparoscopic approach, the intestine was pulled out from an elongated umbilical incision wound; the oral side of the resection range was then determined. Either side-to-end or end-to-end anastomosis was performed (Fig. 2). Side-to-end anastomosis was considered the preferred approach beginning in January 2017; however, end-to-end anastomosis was typically applied when tension at the anastomosis site was expected to be high, as determined by the surgeons. In the side-to-end anastomosis group, the anvil of the circular stapler was inserted into the lumen of the open end; the antimesenteric wall of the intestine was then stapled approximately $3-4 \mathrm{~cm}$ from the open end. The open end was stapled with the same stapler. In the end-to-end anastomosis group, the anvil of the circular stapler was fixed at the open end. The splenic flexure was often mobilized to avoid tension at the anastomosis site in both groups, as determined by the surgeons. Following anastomosis, a drain was placed near the anastomosis region. The need for intraoperative ICG-FA, stoma diversion, or trans-anal tube placement was determined by the surgeons. A charge-coupled device camera (HyperEye Medical System ${ }^{\mathrm{TM}}$; HEMS, Mizuho) was used for ICG-FA, following dissection of the intestine. The anesthesiologist injected $0.25 \mathrm{mg} / \mathrm{kg}$ ICG, followed by flash-injection of $10 \mathrm{ml}$ of saline. When fluorescent labeling at the intended dissection site was poor, the site was modified to a well-perfused proximal site, as determined by the surgeons.

Definition of postoperative complications. Postoperative complications included AL, ileus, and surgical site infections defined as Grade II or higher, according to the Clavien-Dindo classification. The definition of AL was both clinical (i.e., fever, abdominal pain, drain contents, and enhanced inflammatory response) and radiological (i.e., computed tomography scan and contrast enema study). AL in this study included peritonitis due to leakage from any staple line or a pelvic abscess near the anastomosis region, with or without a proven defect in the intestinal wall of the anastomosis, as verified by both clinical and radiological investigations. Patients with AL in this study included those who were diagnosed during their initial hospital stay or after discharge. Leakage verified by either clinical or radiological investigations was not included.

Perioperative management. Mechanical bowel preparation was performed 1 and 2 days before surgery. Sodium picosulfate hydrate ( $5 \mathrm{ml}$; sodium picosulfate solution $0.75 \%$ ) was used 2 days before surgery. Magnesium citrate (100 g; MAGCOROL P) and sodium picosulfate hydrate $(5 \mathrm{ml}$; sodium picosulfate solution $0.75 \%$ ) were used 1 day before surgery. Patients were only permitted to drink clear liquid after mechanical bowel preparation. No chemical bowel preparation was performed.

Patients were permitted to drink clear liquids on the day of surgery. The trans-anal tube was removed on day 3 after surgery, and patients were permitted to take liquid food on day 4. Blood and abdominal X-ray examinations were performed on days $1,3,5$, and 7 after surgery.

Statistical analysis. The Mann-Whitney U test and Fisher's exact test were used to analyze continuous and categorical variables, respectively. Multivariate logistic regression analysis was conducted to identify factors related to $\mathrm{AL}$ at $\mathrm{P}<0.05$. Covariates for multivariate analysis that were statistically significant on univariate analysis $(\mathrm{P}<0.05)$ were included in the multivariate model. All statistical analyses were performed using R software (R Foundation for Statistical Computing, Vienna, Austria), and a $\mathrm{P}$-value $<0.05$ was considered statistically significant.

\section{Results}

Patient characteristics and surgical outcomes. In total, 162 patients (89 men and 73 women) who underwent anterior resection with anastomosis using a double-stapling technique were divided into the side-to-end or end-to-end anastomosis groups between January 2012 and December 2019. Side-to-end anastomosis was performed in 63 patients ( 31 men and 32 women); end-to-end anastomosis was performed in 99 patients (58 men and 41 women). The characteristics of the patients and tumors are shown in Table I. The side-to-end anastomosis group tended to more frequently exhibit tumor locations in the lower rectum, compared to the end-to-end anastomosis group (end-to-end anastomosis group: RS/upper rectum ( $n=93)$, lower rectum $(n=6)$, side-to-end anastomosis group: RS/upper rectum $(n=49)$, lower rectum $(\mathrm{n}=14), \mathrm{P}<0.01)$. No significant differences were observed in other characteristics between the two groups. 
Table I. Patient characteristics.

\begin{tabular}{|c|c|c|c|c|}
\hline Characteristics & Overall & End-to-end anastomosis & Side-to-end anastomosis & P-value \\
\hline Patients, $\mathrm{n}$ & 162 & 99 & 63 & \\
\hline Age, years, median (IQR) & $63(55-71)$ & $64(55-71)$ & $62(56-71)$ & 0.74 \\
\hline Sex, male/female, $\mathrm{n}$ & $89 / 73$ & $58 / 41$ & $31 / 32$ & 0.26 \\
\hline BMI, kg/m², median (IQR) & $22.1(20.3-24.5)$ & $22.5(20.5-24.4)$ & $21.9(20.3-23.9)$ & 0.32 \\
\hline Smoking, $\mathrm{n}$ & 47 & 30 & 17 & 0.72 \\
\hline Cardiovascular disease, $\mathrm{n}$ & 34 & 33 & 21 & 1.00 \\
\hline Lung disease, $\mathrm{n}$ & 18 & 10 & 8 & 0.62 \\
\hline Liver disease, $\mathrm{n}$ & 3 & 1 & 2 & 0.56 \\
\hline Renal disease, $\mathrm{n}$ & 3 & 2 & 1 & 1.00 \\
\hline Diabetes mellitus, $\mathrm{n}$ & 27 & 16 & 11 & 0.83 \\
\hline Preoperative chemoradiation therapy, $\mathrm{n}$ & 3 & 0 & 3 & 0.06 \\
\hline Albumin, g/dl, median (IQR) & $4.3(4.1-4.6)$ & $4.4(4.1-4.6)$ & $4.3(4.0-4.5)$ & 0.40 \\
\hline Location & & & & $<0.01$ \\
\hline $\mathrm{RS} /$ upper rectum, $\mathrm{n}$ & 142 & 93 & 49 & \\
\hline Lower rectum, n & 20 & 6 & 14 & \\
\hline Tumor size, mm, median (IQR) & $40(25-55)$ & $38(25-55)$ & $41(26-53)$ & 0.62 \\
\hline pStage $^{\mathrm{a}}, \mathrm{n}$ & & & & 0.19 \\
\hline I & 56 & 31 & 25 & \\
\hline II & 31 & 24 & 7 & \\
\hline III & 61 & 35 & 26 & \\
\hline IV & 14 & 9 & 5 & \\
\hline
\end{tabular}

${ }^{a}$ pStage was diagnosed using the Eighth edition tumor-node-metastasis staging system of the American Joint Committee on Cancer and Union for International Cancer Control; IQR, interquartile range; BMI, body mass index; RS, rectosigmoid.

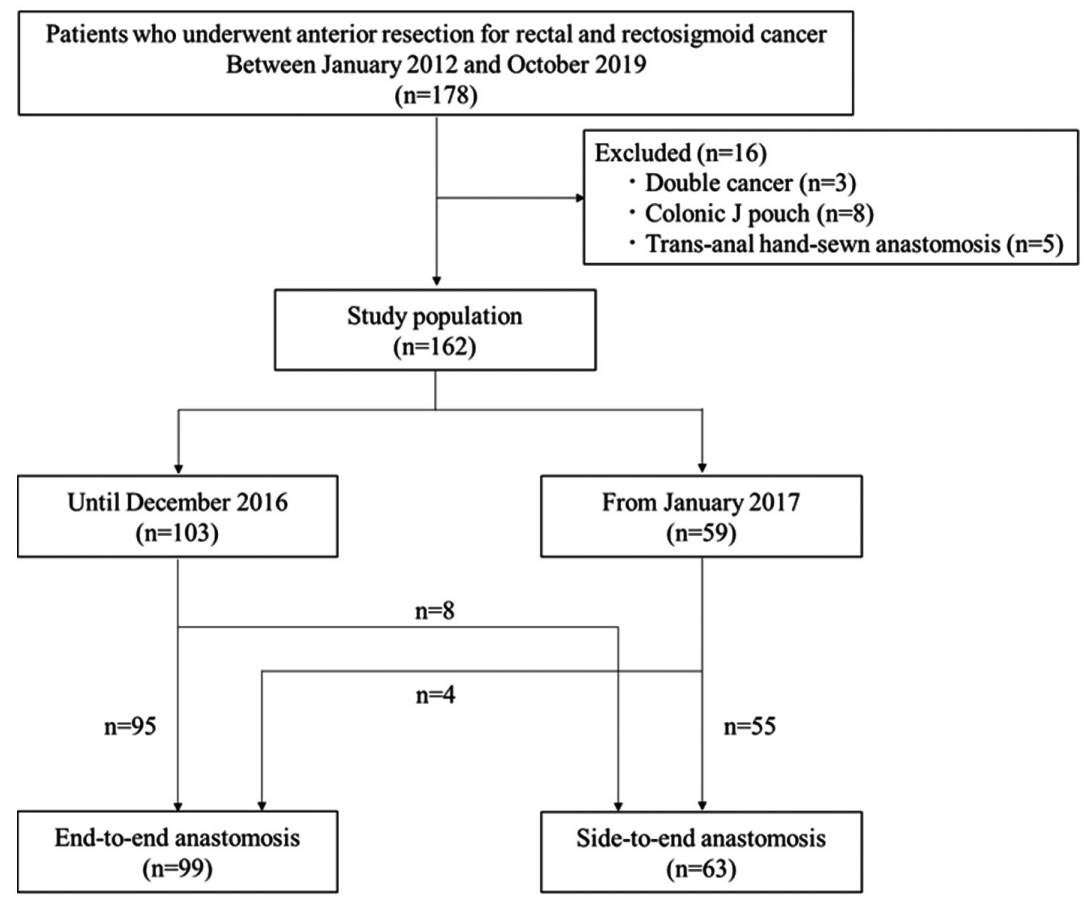

Figure 1. Flow chart of participant inclusion criteria in the present study.

Surgical outcomes are shown in Table II. No significant differences were observed in the approach (open or laparoscopy), surgical type (high or low anterior resection), lymphadenectomy grade, stoma diversion, lateral lymph 
Table II. Surgical outcomes.

\begin{tabular}{|c|c|c|c|c|}
\hline Surgical outcomes & $\begin{array}{l}\text { Overall } \\
(n=162)\end{array}$ & $\begin{array}{c}\text { End-to-end } \\
\text { anastomosis }(n=99)\end{array}$ & $\begin{array}{c}\text { Side-to-end } \\
\text { anastomosis }(n=63)\end{array}$ & P-value \\
\hline Open/laparoscopy, n & $12 / 150$ & $8 / 91$ & $4 / 59$ & 0.77 \\
\hline Operation, $\mathrm{n}$ & & & & 0.09 \\
\hline HAR & 52 & 37 & 15 & \\
\hline LAR & 110 & 62 & 48 & \\
\hline D-number, $\mathrm{n}$ & & & & 0.38 \\
\hline 3 & 114 & 67 & 47 & \\
\hline 1 or 2 & 48 & 32 & 16 & \\
\hline Diverting stoma, $\mathrm{n}$ & 18 & 7 & 11 & 0.07 \\
\hline Simultaneous resection, $\mathrm{n}$ & 21 & 16 & 5 & 0.16 \\
\hline Lateral lymph node dissection, $\mathrm{n}$ & 14 & 7 & 7 & 0.40 \\
\hline Operation time, min, median (IQR) & $254(208-346)$ & $236(200-298)$ & $305(236-395)$ & $<0.01$ \\
\hline Bleeding volume, ml, median (IQR) & $10(10-23)$ & $10(8-20)$ & $11(10-29)$ & 0.03 \\
\hline Trans-anal tube, $\mathrm{n}$ & 148 & 91 & 57 & 0.78 \\
\hline ICG-FA, n & 114 & 54 & 60 & $<0.01$ \\
\hline Additional resection after ICG-FA, $\mathrm{n}$ & 11 & 7 & 4 & 1 \\
\hline Anastomotic leakage, $\mathrm{n}$ & 21 & 18 & 3 & 0.02 \\
\hline Ileus, $\mathrm{n}$ & 4 & 3 & 1 & 1.00 \\
\hline Surgical site infection, & 3 & 2 & 1 & 1.00 \\
\hline Hospital days, median (IQR) & $12(10-16)$ & $12(10-18)$ & $12(11-16)$ & 0.73 \\
\hline Mortality, n & 0 & 0 & 0 & N/A \\
\hline
\end{tabular}

IQR, interquartile range; HAR, high anterior resection; LAR, low anterior resection; D-number, lymph node dissection degree; ICG-FA, indocyanine green fluorescence angiography; N/A, not applicable.
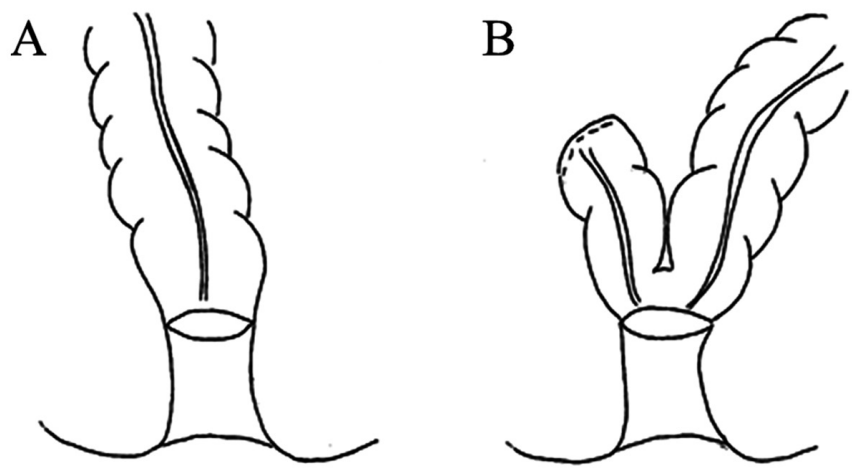

Figure 2. Illustration of anastomosis types. (A) End-to-end anastomosis and (B) side-to-end anastomosis.

node dissection, or trans-anal tube placement. The mean operating time was significantly longer in the side-to-end anastomosis group than in the end-to-end anastomosis group (236 vs. $305 \mathrm{~min}, \mathrm{P}<0.01$ ). Blood loss was also significantly greater in the side-to-end anastomosis group than in the end-to-end anastomosis group (10 vs. $11 \mathrm{ml}, \mathrm{P}=0.03)$. The rate of ICG-FA performance was higher in the side-to-end anastomosis group than in the end-to-end anastomosis group. Notably, no significant difference was observed in terms of additional colon resection after ICG-FA. The AL rate was significantly lower in the side-to-end anastomosis group than in the end-to-end anastomosis group (4.8 vs. $18.2 \%, \mathrm{P}=0.02$ ). Finally, no significant differences were observed between the groups in the incidence rates of other complications, nor in the number of postoperative hospital days.

Furthermore, propensity score matching (PSM) was used to minimize the effects of potential confounders. The propensity score was calculated for each patient with variables (age, sex, BMI, smoking, preoperative chemoradiation therapy, location, tumor size, pStage, diverting stoma, ICG-FA, trans-anal tube) that were not equally distributed and were thought to be confounding factors between the two groups. In PSM, one-to-one matching between the groups was performed using the nearest neighbor matching method with a caliper width of 0.2. By PSM, 36 cases were selected in each group. Although not significantly different after PSM, the rate of AL still tended to be lower in the side-to-end anastomosis group than the end-to-end anastomosis group (5.6 vs. 19.4\%, $\mathrm{P}=0.15$ ) (Tables SI and SII).

Factors associated with anastomotic leakage. Based on these data, we investigated the factors associated with AL. The results of univariate and multivariate analyses of these factors are shown in Table III. Univariate analysis revealed that $\mathrm{AL}$ was significantly associated with a smoking habit, blood loss (>100 ml), anastomosis type (side-to-end anastomosis), and additional colon resection after ICG-FA. Importantly, performance of ICG-FA was not significantly associated with 
Table III. Univariate and multivariate analyses of risk factors associated with anastomotic leakage.

\begin{tabular}{|c|c|c|c|c|c|c|}
\hline \multirow[b]{2}{*}{ Characteristics } & \multicolumn{3}{|c|}{ Univariate analysis } & \multicolumn{3}{|c|}{ Multivariate analysis } \\
\hline & Odds ratio & $95 \% \mathrm{CI}$ & P-value & Odds ratio & $95 \% \mathrm{CI}$ & P-value \\
\hline Age, $>65$ years & 1.25 & $0.50-3.13$ & 0.63 & & & \\
\hline Sex, male & 2.26 & $0.98-6.17$ & 0.11 & & & \\
\hline $\mathrm{BMI}, \geq 25 \mathrm{~kg} / \mathrm{m}^{2}$ & 1.53 & $0.50-4.64$ & 0.45 & & & \\
\hline Smoking & 3.21 & $1.26-8.18$ & 0.02 & 2.84 & $1.04-7.77$ & 0.04 \\
\hline Cardiovascular disease & 0.78 & $0.28-2.13$ & 0.62 & & & \\
\hline Lung disease & 2.13 & $0.63-7.24$ & 0.22 & & & \\
\hline Liver disease & 0.92 & $0.05-18.44$ & 1.00 & & & \\
\hline Renal disease & 0.92 & $0.05-18.44$ & 1.00 & & & \\
\hline Diabetes mellitus & 0.22 & $0.03-1.72$ & 0.15 & & & \\
\hline Preoperative chemoradiation therapy & 0.92 & $0.05-18.44$ & 1.00 & & & \\
\hline Albumin, $\geq 4.0 \mathrm{mg} / \mathrm{dl}$ & 1.34 & $0.27-6.60$ & 0.72 & & & \\
\hline Location, lower rectum & 1.84 & $0.55-6.15$ & 0.32 & & & \\
\hline pStage, III-IV & 1.65 & $0.65-4.17$ & 0.29 & & & \\
\hline Surgical procedure, laparoscopy & 0.41 & $0.10-1.65$ & 0.21 & & & \\
\hline D-number, D3 & 0.91 & $0.60-1.37$ & 0.65 & & & \\
\hline Diverting stoma & 0.37 & $0.05-2.89$ & 0.34 & & & \\
\hline Simultaneous resection & 1.14 & $0.31-4.26$ & 0.85 & & & \\
\hline Lateral lymph node dissection & 1.97 & $0.50-7.74$ & 0.33 & & & \\
\hline Operation time, $\geq 300 \mathrm{~min}$ & 2.13 & $0.85-5.37$ & 0.11 & & & \\
\hline Bleeding volume, $\geq 100 \mathrm{ml}$ & 3.94 & $1.30-11.90$ & 0.02 & 3.43 & $0.99-12.00$ & 0.05 \\
\hline Trans-anal tube & 2.03 & $0.25-16.40$ & 0.51 & & & \\
\hline ICG-FA & 0.82 & $0.31-2.18$ & 0.69 & & & \\
\hline Additional resection after ICG-FA & 4.50 & $1.19-17.00$ & 0.03 & 4.46 & $0.95-20.90$ & 0.06 \\
\hline Tumor size, $\geq 40 \mathrm{~mm}$ & 1.00 & & 0.37 & & & \\
\hline Anastomosis, side-to-end anastomosis & 0.23 & $0.06-0.80$ & 0.02 & 0.22 & $0.06-0.82$ & 0.02 \\
\hline
\end{tabular}

BMI, body mass index; ICG-FA, indocyanine green fluorescence angiography

AL. Multivariate analysis showed that a smoking habit (odds ratio: $2.84,95 \%$ confidence interval: $1.04-7.77 ; \mathrm{P}=0.04)$ and anastomosis (side-to-end anastomosis, odds ratio: $0.22,95 \%$ confidence interval: $0.06-0.82 ; \mathrm{P}=0.02$ ) were significantly associated with AL.

\section{Discussion}

We evaluated the surgical outcomes of trans-anal side-to-end anastomosis, and identified patient and operative factors associated with AL. The most important finding was that the AL rate was significantly lower in the side-to-end than end-to-end anastomosis group (4.8 vs. $18.2 \%$, respectively, $\mathrm{P}=0.02$ ). After PSM which was used to minimize the effects of potential confounders, the rate of $\mathrm{AL}$ tended to be lower in the side-to-end anastomosis group than the end-to-end anastomosis group. Furthermore, the AL differed significantly according to the method of anastomosis in both univariate and multivariate analyses. Finally, the tumors tended to be located lower down in the side-to-end anastomosis group than in the end-to-end anastomosis group. We suggest that side-to-end anastomosis using a double-stapling technique after anterior resection of rectal cancer may prevent AL. Our findings are important because few similar studies have been reported in the literature.

The mechanism by which the anastomosis method affects the AL rate remains unclear. However, one possible explanation is poorer vascular perfusion at the distal end of the colon, as suggested in a previous randomized study (14). Adequate blood flow at the site of anastomosis is important for the prevention of AL (14-18). Blood flow at the anastomotic site of side-to-end anastomosis may be better than at the anastomotic site of end-to-end anastomosis. In principle, we perform ligation of the inferior mesenteric artery for D3 lymph node dissection. It has been reported that a left colic artery-sparing procedure provides better blood flow to the distal end of the colon but does not contribute to AL $(22,23)$. Further studies are required to determine the impacts of inferior mesenteric artery ligation.

Smoking was a risk factor for AL in the present study. An association between smoking and AL has been reported previously, with reduced mucosal blood flow cited as a possible contributing factor (24-30). In this study, selection bias might have significantly impacted the results because smoking histories were not available. A smoking index would have been useful to discriminate between current and ex-smokers. 
In the present study, operating time was significantly longer in the side-to-end anastomosis group than the end-to-end anastomosis group. There were several reasons for this difference. First, tumors were located more frequently at the lower rectum in the side-to-end anastomosis group. Second, ICG-FA tended to be performed in more patients in the side-to-end anastomosis group. As side-to-end anastomosis was introduced in January 2017 in our hospital, ICG-FA was not routinely performed prior to that time. Third, side-to-end anastomosis generally requires slightly longer than end-to-end anastomosis. However, the location of the tumor and performance of ICG-FA, rather than the type of anastomosis, may have led to the longer operating time. Notably, significantly more blood was lost in the side-to-end anastomosis group than in the end-to-end anastomosis group. Tumor location, rather than the type of anastomosis, may have been the main reason for the blood loss.

This study had some limitations. First, the criteria to determine side-to-end anastomosis or end-to-end anastomosis were partially subjective. Tension at the anastomosis site was determined by the surgeon, and it is sometimes difficult to determine whether high tension is present. An objective evaluation of tension at the anastomosis site and objective criteria for selection of anastomosis type are needed. Second, this was a small-scale, retrospective, single-center study and the number of cases of AL was small, so the results might have been subject to various biases, although biases were reduced by PSM. Third, smoking history data were not available and a detailed review was not conducted, which might have enabled the use of a smoking index and discrimination between current smokers and ex-smokers. Fourth, it has been reported that side-to-end anastomosis may be superior to end-to-end anastomosis in terms of postoperative bowel function; however, no comparison of functional outcome was performed between side-to-end anastomosis and end-to-end anastomosis in the present study $(19,20,31-35)$. Fifth, data are not available about the intactness of the mesorectum and the CRM status of the resected specimens in the two groups. It is difficult to demonstrate the usefulness of a single factor for preventing AL, because AL is multifactorial. Prospective, randomized controlled, and multi-institutional studies are required to validate these findings.

Inconclusion, side-to-end anastomosis with a double-stapling technique might be useful for prevention of $\mathrm{AL}$, following AR. Further large-scale randomized controlled trials are required to validate the usefulness of side-to-end anastomosis for reducing the rate of $\mathrm{AL}$ in patients who undergo $\mathrm{AR}$.

\section{Acknowledgements}

Not applicable.

\section{Funding}

No funding was received.

\section{Availability of data and materials}

The datasets used and/or analyzed during the current study are available from the corresponding author on reasonable request.

\section{Authors' contributions}

HK, TI, NN, AK, TT, SI, TO, AK, TH, JN, SM, MM, MT and OI conceived the study concept and design, and were involved in data interpretation. HK, TI, NN, AK, JN and SM were involved in data collection. TI and NN confirm the authenticity of all the raw data. HK, TI, SM and MT performed the data analysis. All authors have read and approved the final manuscript.

\section{Ethics approval and consent to participate}

This study was approved by the institutional review board of the International University of Health and Welfare Mita Hospital (Minato-ku, Japan; approval no. 5-19-41), and disclosed in the form of opt-out. The informed consent forms for treatment included consent for the use of patient data and materials for research purposes.

\section{Patient consent for publication}

Not applicable.

\section{Competing interests}

The authors declare that they have no competing interests.

\section{References}

1. OrtizH, Wibe A, Ciga MA, Kreisler E, Garcia-Granero E, Roig JV and Biondo S; Spanish Rectal Cancer Project: Multicenter study of outcome in relation to the type of resection in rectal cancer. Dis Colon Rectum 57: 811-822, 2014.

2. van der Pas MH, Haglind E, Cuesta MA, Fürst A, Lacy AM, Hop WC and Bonjer HJ; COlorectal cancer Laparoscopic or Open Resection II (COLOR II) Study Group: Laparoscopic versus open surgery for rectal cancer (COLOR II): Short-term outcomes of a randomised, phase 3 trial. Lancet Oncol 14: 210-218, 2013.

3. Park JS, Choi GS, Kim SH, Kim HR, Kim NK, Lee KY, Kang SB, Kim JY, Lee KY, Kim BC, et al: Multicenter analysis of risk factors for anastomotic leakage after laparoscopic rectal cancer excision: The Korean laparoscopic colorectal surgery study group. Ann Surg 257: 665-671, 2013.

4. Rahbari NN, Weitz J, Hohenberger W, Heald RJ, Moran B, Ulrich A, Holm T, Wong WD, Tiret E, Moriya Y, et al: Definition and grading of anastomotic leakage following anterior resection of the rectum: A proposal by the International Study Group of Rectal Cancer. Surgery 147: 339-351, 2010.

5. Rullier E, Laurent C, Garrelon JL, Michel P, Saric J and Parneix M: Risk factors for anastomotic leakage after resection of rectal cancer. Br J Surg 85: 355-358, 1998.

6. Chang SC, Lin JK, Yang SH, Jiang JK, Chen WC and Lin TC: Long-term outcome of anastomosis leakageaftercurative resection for mid and low rectal cancer. Hepatogastroenterology 50: 1898-1902, 2003.

7. Dehni N, Parc R and Church JM: Colonic J-pouch-anal anastomosis for rectal cancer. Dis Colon Rectum 46: 667-675, 2003.

8. Sciuto A, Merola G, De Palma GD, Sodo M, Pirozzi F, Bracale UM and Bracale U: Predictive factors for anastomotic leakage after laparoscopic colorectal surgery. World J Gastroenterol 24: 2247-2260, 2018

9. Akiyoshi T, Ueno M, Fukunaga Y, Nagayama S, Fujimoto Y, Konishi T, Kuroyanagi $\mathrm{H}$ and Yamaguchi T: Effect of body mass index on short-term outcomes of patients undergoing laparoscopic resection for colorectal cancer: A single institution experience in Japan. Surg Laparosc Endosc Percutan Tech 21: 409-414, 2011.

10. Hamabe A, Ito M, Nishigori H, Nishizawa $\mathrm{Y}$ and Sasaki T: Preventive effect of diverting stoma on anastomotic leakage after laparoscopic low anterior resection with double stapling technique reconstruction applied based on risk stratification. Asian J Endosc Surg 11: 220-226, 2018. 
11. Tanaka K, Okuda J, Yamamoto S, Ito M, Sakamoto K, Kokuba Y, Yoshimura K and Watanabe M: Risk factors for anastomotic leakage after laparoscopic surgery with the double stapling technique for stage 0/I rectal carcinoma: A subgroup analysis of a multicenter, single-arm phase II trial. Surg Today 47: 1215-1222, 2017.

12. Moran BJ: Predicting the risk and diminishing the consequences of anastomotic leakage after anterior resection for rectal cancer. Acta Chir Iugosl 57: 47-50, 2010.

13. Testini M, Margari A, Amoruso M, Lissidini G and Bonomo GM: The dehiscence of colorectal anastomoses: The risk factors. Ann Ital Chir 71: 433-440, 2000 (In Italian).

14. Hallböök O, Johansson K and Sjödahl R: Laser Doppler blood flow measurement in rectal resection for carcinoma - comparison between the straight and colonic J pouch reconstruction. Br J Surg 83: 389-392, 1996.

15. Dennett ER and Parry BR: Misconceptions about the colonic J-pouch: What the accumulating data show. Dis Colon Rectum 42: 804-811, 1999.

16. Floodeen H, Hallböök O, Rutegård J, Sjödahl R and Matthiessen P: Early and late symptomatic anastomotic leakage following low anterior resection of the rectum for cancer: Are they different entities? Colorectal Dis 15: 334-340, 2013.

17. Chung RS: Blood flow in colonic anastomoses. Effect of stapling and suturing. Ann Surg 206: 335-339, 1987.

18. Qu H, Liu Y and Bi DS: Clinical risk factors for anastomotic leakage after laparoscopic anterior resection for rectal cancer: A systematic review and meta-analysis. Surg Endosc 29: 3608-3617, 2015.

19. Rubin F, Douard R and Wind P: The functional outcomes of coloanal and low colorectal anastomoses with reservoirs after low rectal cancer resections. Am Surg 80: 1222-1229, 2014.

20. Hüttner FJ, Tenckhoff S, Jensen K, Uhlmann L, Kulu Y, Büchler MW, Diener MK and Ulrich A: Meta-analysis of reconstruction techniques after low anterior resection for rectal cancer. Br J Surg 102: 735-745, 2015.

21. Rybakov EG, Pikunov DY, Fomenko OY, Chernyshov SV and Shelygin YA: Side-to-end vs. straight stapled colorectal anastomosis after low anterior resection: Results of randomized clinical trial. Int J Colorectal Dis 31: 1419-1426, 2016

22. Seike K, Koda K, Saito N, Oda K, Kosugi C, Shimizu K and Miyazaki M: Laser Doppler assessment of the influence of division at the root of the inferior mesenteric artery on anastomotic blood flow in rectosigmoid cancer surgery. Int J Colorectal Dis 22: 689-697, 2007.

23. Akagi T, Inomata M, Hara T, Mizusawa J, Katayama H, Shida D, Ohue M, Ito M, Kinugasa Y, Saida Y, et al: Clinical impact of D3 lymph node dissection with left colic artery (LCA) preservation compared to D3 without LCA preservation: Exploratory subgroup analysis of data from JCOG0404. Ann Gastroenterol Surg 4: 163-169, 2020.
24. Bertelsen CA, Andreasen AH, Jørgensen T and Harling H; Danish Colorectal Cancer Group: Anastomotic leakage after anterior resection for rectal cancer: Risk factors. Colorectal Dis 12: $37-43,2010$

25. Richards CH, Campbell V, Ho C, Hayes J, Elliott T and Thompson-Fawcett M: Smoking is a major risk factor for anastomotic leak in patients undergoing low anterior resection. Colorectal Dis 14: 628-633, 2012.

26. Kim MJ, Shin R, Oh HK, Park JW, Jeong SY and Park JG: The impact of heavy smoking on anastomotic leakage and stricture after low anterior resection in rectal cancer patients. World J Surg 35: 2806-2810, 2011.

27. Kruschewski M, Rieger H, Pohlen U, Hotz HG and Buhr HJ: Risk factors for clinical anastomotic leakage and postoperative mortality in elective surgery for rectal cancer. Int J Colorectal Dis 22: 919-927, 2007.

28. Vignali A, Gianotti L, Braga M, Radaelli G, Malvezzi L and Di Carlo V: Altered microperfusion at the rectal stump is predictive for rectal anastomotic leak. Dis Colon Rectum 43: 76-82, 2000.

29. Fawcett A, Shembekar M, Church JS, Vashisht R, Springall RG and Nott DM: Smoking, hypertension, and colonic anastomotic healing; a combined clinical and histopathological study. Gut 38: 714-718, 1996.

30. Emmanuel AV and Kamm MA: Laser Doppler measurement of rectal mucosal blood flow. Gut 45: 64-69, 1999.

31. Parc Y, Ruppert R, Fuerst A, Golcher H, Zutshi M, Hull T, Tiret E, Hemminger F, Galandiuk S, Fender S, et al: Better Function With a Colonic J-Pouch or a Side-to-end Anastomosis? A randomized controlled trial to compare the complications, functional outcome, and quality of life in patients with low rectal cancer after a J-Pouch or a side-to-end anastomosis. Ann Surg 269: 815-826, 2019.

32. Machado M, Nygren J, Goldman S and Ljungqvist O: Similar outcome after colonic pouch and side-to-end anastomosis in low anterior resection for rectal cancer: A prospective randomized trial. Ann Surg 238: 214-220, 2003.

33. Machado M, Nygren J, Goldman S and Ljungqvist O: Functional and physiologic assessment of the colonic reservoir or side-to-end anastomosis after low anterior resection for rectal cancer: A two-year follow-up. Dis Colon Rectum 48: 29-36, 2005.

34. Siddiqui MR, Sajid MS, Woods WG, Cheek E and Baig MK: A meta-analysis comparing side to end with colonic J-pouch formation after anterior resection for rectal cancer. Tech Coloproctol 14: 113-123, 2010.

35. Fazio VW, Zutshi M, Remzi FH, Parc Y, Ruppert R, Fürst A, Celebrezze J Jr, Galanduik S, Orangio G, Hyman N, et al: A randomized multicenter trial to compare long-term functional outcome, quality of life, and complications of surgical procedures for low rectal cancers. Ann Surg 246: 481-490, 2007. 